\title{
Antibiotic Utilization Trends in Two State Hospitals of Mongolia from 2013 to 2017
}

\author{
Gereltuya Dorj $\mathbb{D}^{1}{ }^{1}$ Hege Salvesen Blix $\mathbb{D}^{\mathrm{D}},{ }^{2}$ Bruce Sunderland, ${ }^{3}$ Badamkhand Gankhulug, \\ Otgonbileg Tegshee, ${ }^{4}$ Mandakhnaran Purevkhuu, ${ }^{1}$ Gansaruul Shirnen, ${ }^{5}$ \\ Tsetsegmaa Sanjjav, ${ }^{1}$ Gantuya Dorj, ${ }^{6}$ and Byambatsogt Gendenragchaa ${ }^{1}$
}

\author{
${ }^{1}$ School of Pharmacy, Mongolian National University of Medical Sciences, S.Zorig street, Sukhbaatar district, 14210 Ulaanbaatar, \\ Mongolia \\ ${ }^{2}$ Norwegian Institute of Public Health and School of Pharmacy, University of Oslo, Postboks 1068 Blindern 0316 OSLO, Norway \\ ${ }^{3}$ School of Pharmacy, Curtin University of Technology, GPO Box U1987, Perth 6845, Australia \\ ${ }^{4}$ Department of Pharmacy, State Third Hospital of Mongolia, Ard-Ayush avenue, 6th khoroo, Bayangol district, 16000 Ulaanbaatar, \\ Mongolia \\ ${ }^{5}$ Department of Pharmacy, State Second Hospital of Mongolia, S.Zorig street, Sukhbaatar district, 210648 Ulaanbaatar, Mongolia \\ ${ }^{6}$ School of Public Health, Mongolian National University of Medical Sciences, S.Zorig street, Sukhbaatar district, 14210 Ulaanbaatar, \\ Mongolia
}

Correspondence should be addressed to Hege Salvesen Blix; HegeSalvesen.Blix@fhi.no

Received 15 March 2019; Accepted 6 August 2019; Published 7 October 2019

Guest Editor: Bach X. Tran

Copyright (C) 2019 Gereltuya Dorj et al. This is an open access article distributed under the Creative Commons Attribution License, which permits unrestricted use, distribution, and reproduction in any medium, provided the original work is properly cited.

\begin{abstract}
Background. The study aimed to evaluate inpatient antibiotic use in both the State Second Hospital and State Third Hospital in Mongolia, using the WHO developed and standardized ATC/DDD methodology. Methods. Data were collected from the State Second Hospital and State Third Hospital which are major public hospitals that provide health care for approximately one fifth of the Mongolian population. Antibiotic utilization was monitored retrospectively for five years (2013-2017) using the ATC/DDD methodology and data were presented in DDD/ admission and DDD/100 bed days. Statistical analysis was performed using a Student's t-test for parametric data. A $P$ value of $\leq 0.05$ was considered to be statistically significant. Results. The annual consumption rates in the State Second Hospital were stable over time while in the State Third Hospital consumption rates varied considerately between years. Overall, the total antibiotic consumption rate was very high, but has decreased in both hospitals. The rate of consumption of all antibiotics was approximately twice that in the State Third Hospital (421.7 DDD/100 bed days) between 2013 and 2017 when compared with the State Second Hospital (199.7 DDD/ 100 bed days), $P<0.001$ ). The seven most frequently used antibiotics comprised approximately 75\% of all DDDs in both hospitals, in the period 2013-2017; being: amoxicillin, cefazolin, cefotaxime, ceftriaxone, clarithromycin, ciprofloxacin, and nitroxoline. However, this was not consistent when considering the individual years, since in 2015 and 2016, these seven active agents represented approximately 50\%. Conclusion. This is the first hospital-based study of antibiotic consumption rates reported in Mongolia. In addition to very high consumption rates, large differences occurred between the hospitals investigated. Inappropriate and high levels of antibiotic use lead to increased costs and also increased nosocomial infection rates with potentially resistant species. The Government and health professionals need to take more active roles in improving and promoting quality antibiotic use among inpatients.
\end{abstract}

\section{Introduction}

Antimicrobial resistance (AMR) is threatening current health care practice. Antibiotic use and especially over-use contributes to increased AMR in society, and WHO recommends every country set up surveillance systems for AMR. Drug utilization research is defined as "an eclectic collection of descriptive and analytical methods for the quantification, understanding and the evaluation of the processes of prescribing, dispensing and consumption of medicines, and for the testing of interventions to enhance the quality of these processes" [1]. Drug utilization research is regarded as essential for rational pharmacotherapy; 
TABLE 1: Hospital demographic data for selected years.

\begin{tabular}{|c|c|c|c|c|c|c|c|c|c|c|}
\hline \multirow[b]{2}{*}{ Indicator } & \multicolumn{2}{|c|}{2013} & \multicolumn{2}{|c|}{2014} & \multicolumn{2}{|c|}{2015} & \multicolumn{2}{|c|}{2016} & \multicolumn{2}{|c|}{2017} \\
\hline & $\begin{array}{c}\text { State } \\
\text { second } \\
\text { hospital }\end{array}$ & $\begin{array}{c}\text { State } \\
\text { third } \\
\text { hospital }\end{array}$ & $\begin{array}{c}\text { State } \\
\text { second } \\
\text { hospital }\end{array}$ & $\begin{array}{c}\text { State } \\
\text { third } \\
\text { hospital }\end{array}$ & $\begin{array}{c}\text { State } \\
\text { second } \\
\text { hospital }\end{array}$ & $\begin{array}{c}\text { State } \\
\text { third } \\
\text { hospital }\end{array}$ & $\begin{array}{c}\text { State } \\
\text { second } \\
\text { hospital }\end{array}$ & $\begin{array}{c}\text { State } \\
\text { third } \\
\text { hospital }\end{array}$ & $\begin{array}{c}\text { State } \\
\text { second } \\
\text { hospital }\end{array}$ & $\begin{array}{c}\text { State } \\
\text { third } \\
\text { hospital }\end{array}$ \\
\hline No of inpatients & 7,561 & 17,064 & 7,518 & 17,057 & 8,189 & 17,536 & 8,518 & 18,539 & 9,126 & 19,491 \\
\hline $\begin{array}{l}\text { No of beds per } \\
10000 \\
\text { inhabitants }\end{array}$ & 1.01 & 2.021 & 0.998 & 1.996 & 0.999 & 1.997 & 0.985 & 1.970 & 0.973 & 2.054 \\
\hline $\begin{array}{l}\text { Average length } \\
\text { of stay per } 10000 \\
\text { inhabitants }\end{array}$ & 0.041 & 0.039 & 0.041 & 0.037 & 0.038 & 0.036 & 0.036 & 0.034 & 0.033 & 0.033 \\
\hline
\end{tabular}

it investigates what is being used by evaluating the appropriateness of prescribing and use of medicines [2]. Drug utilization studies of antimicrobial use may create awareness and understanding of the volume of use and potential consequences for AMR from the use of antibiotics in the human and animal health sectors. The use of antibiotics varies substantially among countries [3-6]. Due to different types of health care organizations, variations occur among hospitals within a country, indicating the need for common methodology to facilitate interhospital and longitudinal comparisons. Antibiotic utilization has been monitored frequently at outpatient and inpatient levels in many countries, particularly in high-income countries; however limited data are available from less developed nations. Drug use data have until now not been collected in Mongolia and there is a need to perform such studies, to set a baseline, and when appropriate develop effective interventions towards rational drug prescribing. Recently, the WHO reported antibiotic surveillance of consumption data worldwide, with Mongolia one of the countries with the highest antibiotic consumption (64.4 DDD per 1000 inhabitants per day). However, these data were collected from the records of imported and locally manufactured antibiotics and not at the patient level. These records of imported and locally produced antibiotics were retrieved from an online database, managed by the Center for Health Development, Ministry of Health, Mongolia [7]. Drug utilization studies should be conducted at the end-user level [1]. However, no data regarding medicine utilization statistics are available for any of the hospitals in Mongolia.

This study aimed to evaluate inpatient antibiotic use in both the State Second Hospital and State Third Hospital in Mongolia, using the WHO developed and standardized ATC/ DDD methodology.

\section{Materials and Methods}

2.1. Study Design. A retrospective longitudinal analysis of antibiotic consumption data from two selected state hospitals of Mongolia was completed for the period from 2013 to 2017.

2.2. Setting. In Mongolia, there are 13 central hospitals and specialized centers which provide tertiary level care, 5 Regional Diagnostic Treatment Centers, 16 aimag (province) general hospitals, 12 district general hospitals and health centers, 6 provincial general hospitals provide secondary level care, 39 inter-soum (second level subdivision) hospitals, 273 soum general hospitals, 218 family group practices that provide primary level care. In addition, there are 240 private inpatient hospitals and 1226 outpatient hospitals [8]. The study has included data from two public central hospitals that provide tertiary health care for approximately one fifth of the Mongolian population. Antibiotic utilization was monitored longitudinally for five years (2013-2017) at the Second and Third State Central Hospitals of Mongolia. These two state central hospitals provided health care and comprised of 23 wards covering most branches of medicine with a total of 28,617 inpatients (19.1\%) of the 149,648 total number of inpatients admitted to 13 central hospitals and specialized centers in the country (2017). The annual number of in-hospital admissions were 9,126 in the Second Hospital and 19,491 in the Third Hospital in 2017 [9]. Data regarding the bed number and bed days were relatively stable for both hospitals over the selected years (Table 1) [10, 11]. Hospital wards and corresponding bed numbers are provided in Table 2.

2.3. Data Collection. In Mongolia, the pharmaceutical procurement sector is $100 \%$ privatized. Medicines are distributed through organizations such as drug wholesalers and retail drug outlets (community pharmacies and revolving drug funds). Medicines are usually supplied to state central hospitals through purchasing by tender from private pharmaceutical companies, wholesalers, as well as distributors.

In this study, reports submitted by the Pharmacy Departments of each hospital to the Statistics Office and hospital purchases from pharmaceutical wholesalers were used to capture the total hospital antibiotic utilization.

As specified in the Law of Mongolia on Procurement of Goods, Works and Services with State and Local Funds [12], medicines and medical devices are procured through an open-tender [12]. The evaluation is based on criteria set by the Drug Therapeutic Coordination Committee of each hospital and the tender with the lowest price is evaluated as "the best" and deemed high value for comparison and estimation to procuring the medical equipment, tools and drugs. A successful wholesaler or tenderer will supply and deliver goods, including medicines to the Hospital Pharmacy Department. Hence, all wards of the two state hospitals receive 
TABLE 2: Name of wards and corresponding bed number in two selected hospitals.

\begin{tabular}{lcc}
\hline Name of Wards & $\begin{array}{c}\text { State second hospital } \\
(2013-2017)\end{array}$ & $\begin{array}{c}\text { State third hospital } \\
(2013-2017)\end{array}$ \\
\hline Cardiac surgery & 0 & 40 \\
Cardiology & 25 & 45 \\
Gastroenterology & 34 & $36-40$ \\
General surgery & 50 & 45 \\
Infarction & 0 & 20 \\
Intensive care & 6 & 4 \\
Nephrology, & 20 & $35-40$ \\
Endocrinology & 0 & 48 \\
Neurological surgery & 30 & 42 \\
Neurology & 0 & 20 \\
Ocular surgery & 0 & $20-30$ \\
Otolaryngology & 14 & 0 \\
Pediatrics & 15 & $35-40$ \\
Pulmonology & 5 & 0 \\
Specialized care & 0 & 20 \\
Stroke & 16 & 20 \\
Traditional medicine & 215 & $430-454$ \\
Total number of beds & &
\end{tabular}

medicines from pharmacy departments and at the end of each month the Pharmacy Department compiles a report on medicines given to patients. These public pharmacies are called Pharmacy Departments and they are located in the hospitals and they provide medicines only to inpatients during their hospitalization period in Mongolia, [13] hence only data regarding medicine utilization of patients admitted to hospitals were available from the public hospitals. Medicines given while in the hospital are counted as inpatient medication, if patients are to continue at home they will get a prescription and this will be regarded as used as an outpatient. Outpatients seek medication outside a hospital, often from retail pharmacies located nearby or within the hospital. However, in Mongolia, no data are available regarding the utilization of antibiotics for outpatients. Therefore, the study included records of inpatients who were dispensed antibiotics.

Antibiotic data were identified to be all antibacterials for systemic use, i.e., group J01 of the Anatomical Therapeutic and Chemical (ATC) classification and for classes and subclasses of this group [14]. Data collected included unique chemical substance name, generic name, unit strength, pack size, quantity of packs, route of administration, and manufacturer. DDDs were calculated for each product according to the ATC/DDD methodology, ATC/DDD Index 2014 [15]. DDD per 1000 inhabitants per year is only recommended for international comparison.

2.4. Data Management and Analysis. All data were recorded in and analyzed by Microsoft Excel 2016. Data validation was completed by means of ESAC checklist [16] for possible biases, including population and medicine coverage.

As the WHO recommends, if medicine utilization is assessed among inpatients, it should be expressed as number of defined daily doses used either per admission (DDD/ admissions, bed days (DDD/100 bed days) and/or per 1000 inhabitants (DID/1000) [2]. In this study, the population prescribed antibiotics were admitted patients staying at least overnight (24 hours).

The definition of a bed day may differ between hospitals or countries. In this study the common definition for the two hospitals selected was: a bed day is a day during which a person is confined to a bed for a day surgery procedure and/or in which the patient stays overnight in a hospital. Moreover, $\mathrm{DDD} / \mathrm{admission}$ is another indicator that can be used to show antibiotic use according to hospital activity. The day of discharge was also included in the analysis. Both indicators are reported to be important to compare and benchmark in and between hospitals $[17,18]$.

Census data regarding bed days and hospital admissions were obtained from the Statistical Office of the two state hospitals.

The statistical analysis was performed using Student's t-test for parametric data. A $P$ value of $\leq 0.05$ was considered to be statistically significant.

\section{Results}

3.1. Total Antibiotic Consumption. Total antibiotic consumption differed between the hospitals. The consumption in the State Second Hospital was stable over the five years, while the annual consumption in the State Third Hospital varied considerately between years. Overall, the total antibiotic consumption has fluctuated for the State Third Hospital and decreased in the State Second Hospital, from 2013 till 2017 (Figure 1).

Data regarding DDDs per 100 bed days were calculated for both hospitals in the selected years. First and third generation cephalosporins were the highest consumed antibiotics in the State Second Hospital in 2013. In the State Second Hospital, the $1^{\text {st }}$ generation cephalosporins were the highest with $16.6 \mathrm{DDD} / 100$ bed days in 2013 and it decreased to 5.0 in 2017. Moreover, the use of $3^{\text {rd }}$ generation cephalosporins has increased by $13 \%(\mathrm{DDD} / 100$ bed days 11.1 versus 13.0) in the State Second Hospital. The consumption of metronidazole (DDD/100 bed days 0.25 versus 0.5 ) and aminoglycosides (DDD/100 bed days 0.9 versus 1.8 ) have almost doubled in the study period.

On the other hand, significantly higher DDD/100 bed days for systemic antibiotic classes were reported from the State Third Hospital. DDDs/100 bed days for systemic (J01) antibiotics consumed at the State Third Hospital showed to be decreasing in the study period (2013: $205.3 \mathrm{DDD} / 100$ bed days, 2017: 138.7 DDD/100 bed days). However, a contrary result occurred for macrolides, $3^{\text {rd }}$ generation cephalosporins, aminoglycosides, and combination of penicillins were observed. Increase in consumption of $3^{\text {rd }}$ generation cephalosporins was the highest (DDD/100 bed days 4.2 versus 15.7 DDD/100 bed days) for macrolides were 13.7 in 2013 and they have increased rapidly to 24.7 in 2017 (Table 3).

3.2. Class-Specific Trends. The average consumption of systemic antibiotics was approximately twice in the State 


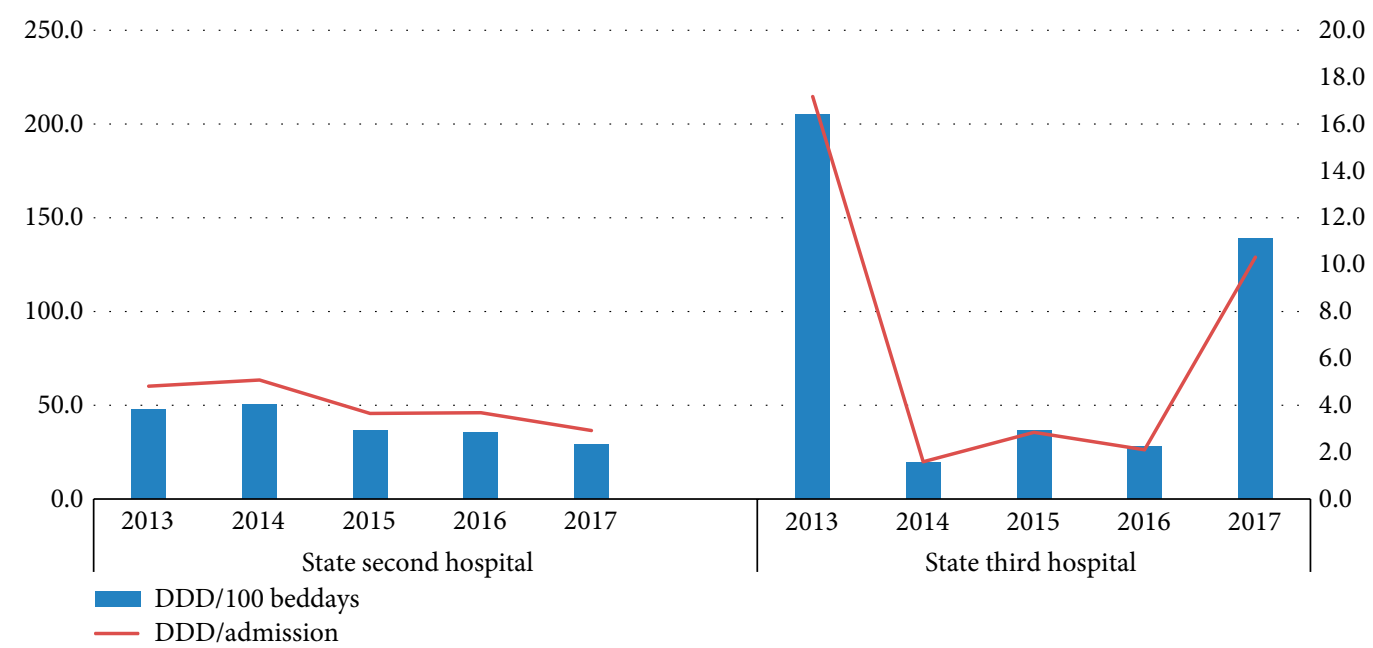

FIgURE 1: Total use of antibiotics as DDDs/admission and DDD/100 bed days in the two state hospitals in Mongolia (2013-2017).

TABLE 3: DDDs per 100 bed days in the two state hospitals for 2013-2017.

\begin{tabular}{|c|c|c|c|c|c|c|c|c|c|c|}
\hline $\begin{array}{l}\text { Antimicrobial class } \\
\text { (ATC code) }\end{array}$ & $\begin{array}{c}\text { State } \\
\text { second } \\
\text { hospital }\end{array}$ & $\begin{array}{l}\text { State third } \\
\text { hospital } \\
013\end{array}$ & $\begin{array}{c}\text { State } \\
\text { second } \\
\text { hospital }\end{array}$ & $\begin{array}{l}\text { State third } \\
\text { hospital } \\
014\end{array}$ & $\begin{array}{c}\begin{array}{c}\text { State } \\
\text { second } \\
\text { hospital }\end{array} \\
2\end{array}$ & $\begin{array}{l}\text { State third } \\
\text { hospital } \\
015\end{array}$ & $\begin{array}{c}\text { State } \\
\text { second } \\
\text { hospital }\end{array}$ & $\begin{array}{l}\text { State third } \\
\text { hospital } \\
016\end{array}$ & $\begin{array}{l}\text { State second } \\
\text { hospital } \\
\\
20\end{array}$ & $\begin{array}{l}\text { State third } \\
\text { hospital } \\
17\end{array}$ \\
\hline $\begin{array}{l}\text { Penicillins with extended } \\
\text { spectrum (J01CA) }\end{array}$ & 4.0 & 28.6 & 4.2 & 2.8 & 1.5 & 1.0 & 1.5 & 0.0 & 0.6 & 18.3 \\
\hline $\begin{array}{l}\text { Other penicillins } \\
\text { (J01CE/J01CR) }\end{array}$ & 1.5 & 15.0 & 1.5 & 0.5 & 1.7 & 3.9 & 1.7 & 2.9 & 1.4 & 6.3 \\
\hline $\begin{array}{l}\text { 1st gen. cephalosporins } \\
\text { (J01CD) }\end{array}$ & 16.6 & 27.1 & 14.7 & 2.1 & 7.3 & 0.8 & 7.1 & 1.9 & 5.0 & 18.1 \\
\hline $\begin{array}{l}\text { 3rd gen. cephalosporins } \\
\text { (J01DD) }\end{array}$ & 11.1 & 4.2 & 12.5 & 0.6 & 14.5 & 17.8 & 14.2 & 2.3 & 13.1 & 15.7 \\
\hline Macrolides (J01FA) & 6.6 & 13.7 & 8.2 & 1.0 & 3.9 & 0.6 & 3.8 & 0.9 & 3.0 & 24.7 \\
\hline $\begin{array}{l}\text { Fluoroquinolones } \\
\text { (J01MA) }\end{array}$ & 4.6 & 16.3 & 4.4 & 1.3 & 3.5 & 8.9 & 3.4 & 8.8 & 2.4 & 15.3 \\
\hline Nitroxoline (J01XX07) & 0.6 & 87.1 & 0.7 & 7.0 & 0.5 & 0.2 & 0.5 & 0.0 & 0.5 & 28.3 \\
\hline $\begin{array}{l}\text { Metronidazole } \\
\text { (J01XA/P01BA01) }\end{array}$ & 0.2 & 2.8 & 1.3 & 1.4 & 0.8 & 1.3 & 0.8 & 0.0 & 0.5 & 0.6 \\
\hline Amphenicols (J01B) & 0.5 & 3.1 & 0.2 & 0.2 & 0.1 & 0.5 & 0.1 & 7.4 & 0.1 & 0.0 \\
\hline Other Abs in J01 & 2.1 & 7.2 & 2.9 & 2.5 & 2.6 & 1.5 & 2.5 & 3.7 & 2.7 & 10.9 \\
\hline
\end{tabular}

Third Hospital (421.7 DDD/100 bed days) period when compared with the DDD/100 bed days in the State Second Hospital (199.7 DDD/ 100 bed days) between the 5-year study $\left[\chi^{2}=116.240, d f=4, \chi^{2} / d f=29.06, P\left(\chi^{2}>116.240\right)<0.001\right]$. Overall, the use of $1^{\text {st }}$ generation cephalosporins was similar in both hospitals ( 50.7 vs 49.9 DDD/100 bed days); however, comparatively more $3{ }^{\text {rd }}$ generation cephalosporins were used for inpatient care in the State Second Hospital (65.3 DDD/100 bed days) than in the State Third Hospital (40.7 DDD/100 bed days). On the other hand, the use of nitroxoline (2.8 vs $122 \mathrm{DDD} / 100$ bed days) were 44 times higher in the State Third Hospital than in the State Second Hospital.

There has been increased use of cefotaxime (11.1-13.1 DDD/100 bed days and 4.2-15.7DDD/ 100 bed days) in both hospitals. In addition, use of macrolides were increased (13.7-24.7 DDD/ 100 bed days), as well as the increased use of glycopeptides, vancomycin (72.3-228.6 DDD/100 bed days), and nitrofuran derivates, nitrofurantoin ( 0.2 versus $0.6 \mathrm{DDD} / 100$ bed days) were observed in the State Third Hospital.

There were also large differences between the hospitals when looking at formulations. When looking at the data in 2017, in the State Second Hospital parenteral formulations were frequently used (81.9\%), and in the State Third Hospital oral were most often used (66.4\%) (Figure 2).

3.3. Pattern of Use. The consumption pattern of antibiotics differed between the hospitals. In the Second Hospital, three antibiotic groups; $1^{\text {st }}$ and $3^{\text {rd }}$ generation cephalosporins and the macrolides represented around $70 \%$ of the antibiotic consumption in a five years period (2013-2017). In the Second Hospital, three antibiotic groups; $1^{\text {st }}$ and $3^{\text {rd }}$ generation 




Figure 2: Proportion of oral (O) and parenteral (P) antibiotics in two selected hospitals in Mongolia (2013-2017).

cephalosporins and the macrolides represented around $70 \%$ of the antibiotic consumption in a five years period (2013-2017).

In the State Third Hospital, above mentioned three antibiotic groups represented only $31 \%$, while nitroxoline, fluoroquinolones, and penicillins with extended spectrum represented $52 \%$ of total DDD/admissions in the same period.

The seven most frequently used antibiotics represented around $75 \%$ of all DDDs in both hospitals, in the whole period 2013-2017; these were; amoxicillin (J01CA04), cefazolin, cefotaxime, ceftriaxone, clarithromycin, ciprofloxacin, and nitroxoline. However, this was not true when looking at the separate years, in 2015 and 2016, these substances represented approximately $50 \%$ (Table 4 ).

\section{Discussion}

To the best our knowledge, this is the first study to report the antibiotic consumption in two selected state hospitals of Mongolia, using the WHO methodology. The changes of antibiotic consumption over a five-year period were quantified in order to inform decision makers, medical professionals, and the community.

Antibiotic consumption is the major driver leading to antibiotic resistance. The study has indicated that the consumption has decreased in both hospitals in the study period. Considering the Government's effort to promote appropriate use of antibiotics and reduce antibiotic resistance, antibiotic use was decreased by almost $30 \%$ over the period of study [State Second Hospital: 47.8DDD/100 bed days (2013) vs 29.3 DDD/100 bed days (2013); State Third Hospital: 205.3 DDD/ 100 bed days (2013) vs 138.2 DDD/100 bed days (2017). In addition, this result may be accounted for in part by the greater emphasis on development of recently produced documents, implemented activities $[19,20]$ and State issued regulations [21-23]. Differences in the consumption levels of antimicrobial agents in the two hospitals were observed in this study and it can be related with various factors, including hospital specialties, patient population, and adherence to clinical guidelines and protocols. The State Third Hospital consists of four centers, 11 wards providing hospital care specializing in Cardiology, Neurology, Diabetes, and Consultancy services. In addition, the Third Hospital provides medical care through 25 departments. The State Second Hospital has about 215 beds, 9 wards, in addition to providing ambulatory and inpatient hospital care for all patients in Mongolia, the hospital provides emergency and planned surgeries of residents in Sukhbaatar district, Ulaanbaatar city. Both hospitals should conduct microbiology testing upon administration; however, due to lack of financial resources, routine testing is not performed.

A previous study conducted in two tertiary hospitals in Mongolia found out that $19 \%$ of infections microbiological diagnostics were done and antibiotics were given without sensitivity testing in $92 \%$ of cases [24].

The level of antibiotic use was $84.0 \mathrm{DDD} / 100$ bed days [DDD/100 bed days of 29.3 (State Second Hospital) and 138.7 (State Third Hospital)] and it is still exceeding that from other countries, including Croatia (32.9DDD/100bed days) [25], Norway (47.5DDD/100bed days) [26], and Slovenia (50.4DDD/100 bed days) [27]. Oral antibiotics ranged from $60.3 \%$ to $55.8 \%$ and parenteral antibiotics were almost equal throughout the years, ranging from $39.7 \%$ to $44.2 \%$ in both hospitals combined. However, the individual analysis in this study indicated the State Third Hospital used more oral antibiotics (66.4\%) than parenteral medications (33.6\%). As for the State Second Hospital, parenteral forms were more utilized starting from $71 \%$ in 2013 , increasing to $82 \%$ in 2017 . Differences between consumption of parenteral versus oral forms of antibiotics can be related with hospital specialties, as well as different levels of knowledge and attitude among prescribers practicing in each hospital [28]. Other findings reported the proportion of parenteral DDD being higher (around 70\%) than Tajikistan (31.1\%) [29], but lower than China (98\%) [30].

In general, the findings indicated a decreasing but fluctuating pattern of antibiotic consumption in both hospitals for all medicines. Of the seven most frequent used nitroxoline is the one that is much of interest compared to use elsewhere in the world. The main indication is for urinary tract infections 
TABLE 4: The seven most frequently used antibiotics in two state hospitals of Mongolia, expressed as DDD/100 bed days (2013-2017).

\begin{tabular}{lcccccccccc}
\hline \multirow{2}{*}{$\begin{array}{l}\text { ATC5 name/ } \\
\text { DDD 100 bed } \\
\text { days }\end{array}$} & $\begin{array}{c}\text { State } \\
\text { second } \\
\text { hospital }\end{array}$ & $\begin{array}{c}\text { State } \\
\text { third } \\
\text { hospital }\end{array}$ & $\begin{array}{c}\text { State } \\
\text { second } \\
\text { hospital }\end{array}$ & $\begin{array}{c}\text { State } \\
\text { third } \\
\text { hospital }\end{array}$ & $\begin{array}{c}\text { State } \\
\text { second } \\
\text { hospital }\end{array}$ & $\begin{array}{c}\text { State } \\
\text { third } \\
\text { hospital }\end{array}$ & $\begin{array}{c}\text { State } \\
\text { second } \\
\text { hospital }\end{array}$ & $\begin{array}{c}\text { State } \\
\text { third } \\
\text { hospital }\end{array}$ & $\begin{array}{c}\text { State } \\
\text { second } \\
\text { hospital }\end{array}$ & $\begin{array}{c}\text { State } \\
\text { third } \\
\text { hospital }\end{array}$ \\
\hline Amoxicillin & 2.8 & 27.4 & 3.5 & 2.6 & 1.4 & 1.0 & 1.0 & 0.0 & 0.0 & 18.2 \\
Cefazolin & 16.6 & 27.1 & 14.7 & 2.1 & 9.9 & 0.6 & 7.1 & 1.8 & 0.0 & 18.1 \\
Cefotaxime & 5.9 & 1.5 & 6.7 & 0.0 & 5.0 & 0.1 & 8.4 & 0.4 & 0.0 & 6.6 \\
Ceftriaxone & 5.2 & 2.5 & 5.2 & 0.6 & 3.9 & 0.0 & 5.5 & 1.0 & 0.0 & 9.0 \\
Ciprofloxacin & 2.9 & 13.5 & 1.8 & 0.8 & 1.4 & 0.7 & 1.4 & 2.2 & 0.0 & 15.2 \\
Clarithromycin & 6.5 & 12.9 & 7.9 & 1.0 & 4.8 & 0.4 & 3.8 & 0.8 & 0.0 & 24.3 \\
Nitroxoline & 0.6 & 87.1 & 0.7 & 7.0 & 0.4 & 0.2 & 0.5 & 0.0 & 0.0 & 28.3 \\
Total & 40.5 & 172.2 & 40.4 & 14.1 & 26.8 & 3.1 & 27.6 & 6.3 & 0.1 & 119.8 \\
& $(84.7 \%)$ & $(83.9 \%)$ & $(79.9 \%)$ & $(72.7 \%)$ & $(77.1 \%)$ & $(8.4 \%)$ & $(77.7 \%)$ & $(22.5 \%)$ & $(78.2 \%)$ & $(86.3 \%)$ \\
\hline
\end{tabular}

(UTI) which is reported to be one of the prevalent diseases in Mongolia [8]. A recent literature review on efficacy and tolerance of nitroxoline in the treatment of uncomplicated UTI demonstrated equivalent efficacy of nitroxoline with the controls tested (cotrimoxazole, norfloxacin) and justified the use of nitroxoline as one of the first line antibiotics for the treatment of uncomplicated UTI [31]. Uncomplicated UTI is more likely to be prevalent in the ambulatory setting, on the other hand patients preference for inpatient services and the perceived poor quality of outpatient services have been reported previously [13]. Hence the prescribing practice of nitroxoline at these hospitals should be further investigated and justified.

Existing inappropriate use [32], access and availability of essential medicines [33], lack of knowledge among prescribers and dispensers [28], and hospital specialties could be the main contributors to huge differences between hospitals.

Particularly, fluctuations seemed to have occurred dramatically during 2015-2017. This can be somehow related with Health Minister's Order on increasing the Government Budget for medicines and medical devices to public hospitals. Moreover, fluctuations may also have occurred due to outbreaks of infectious diseases and increasing trend in the development of antimicrobial resistance. The local production of some antibiotics (ceftriaxone, cefotaxime), in addition to commercial promotions may also lead to the increased use of cephalosporins. Availability of newer antibiotics on the market, by the pharmaceutical industry, as well as insufficient knowledge of prescribers [29] may also result in the fluctuating results. On the other hand, the procurement and supply of pharmaceuticals and medical devices are still highly dependent on foreign currency [34]. Procurement is also heavily impacted by financial instability, irregular access to and unavailability of funds. Recently approved guidelines and protocols as well as their compliance and treatment outcomes are yet to be assessed and monitored. Together, the quantity of pharmaceuticals, including antibiotics procured and consumed at public hospitals may have varied.

In addition, the consumption of macrolides was 6.6 DDD/100 bed days $(5.1 \mathrm{DDD} / 100$ bed days in the State Second Hospital, $8.18 \mathrm{DDD} / 100$ bed days in the State Third
Hospital), which is comparable with those reported from Iran (5.8 DDD/100 bed days) [35] and Israel (5.9 DDD/100 bed days) [36]. Moreover, the use of quinolones (6.8 DDD/100 bed days; State Second Hospital: 3.66DDD/100bed days, State Third Hospital: 10.12 DDD/100 bed days) was lower when compared with results from Iran (9.3 DDD/100 bed days) [35] and Israel (10.8 DDD/100 bed days) [36].

Carbapenems $(0.026 \mathrm{DDD} / \mathrm{admission}$ in State Second Hospital, 0.002 DDD/admission in State Third Hospital) and glycopeptides (0.006 DDD/admission in State Second Hospital and $0.005 \mathrm{DDD} / \mathrm{admission}$ in State Third Hospital), often required as last-line treatment for multiresistant bacteria, were used at low levels in two hospitals. This is likely because their use requires pre-authorization due to high cost. Nevertheless, data from the State Second Hospital showed that carbapenem consumption increased by $32.9 \%$ from 0.019 DDD/admission in 2013 to $0.026 \mathrm{DDD} / \mathrm{admission}$ in 2017 . This may be in response to the rising prevalence of Extended-Spectrum Beta-Lactamase (ESBL)-producing bacteria, identified in surveillance studies [37]. Also, a five-time rise in glycopeptide, i.e., vancomycin use (from 0.001 DDD/admission in 2013 to $0.006 \mathrm{DDD} / \mathrm{admission}$ in 2017) was observed in the State Second Hospital. Similarly, the consumption of vancomycin was increased in the State Third Hospital dramatically from 0.001 DDD/admission in 2013 and $0.005 \mathrm{DDD} / \mathrm{admission}$ in 2017.

Increasing rates of MRSA confirmed cases were reported from both hospitals, namely $2 \%(n=369)$ in 2014 to $5 \%(n=560)$ in 2018 in the State Second Hospital [38] and from $0.9 \%(n=216)$ in 2017 to $2 \%(n=436)$ in 2018 in the State Third Hospital [39]. A previous study completed in 4 hospitals of Ulaanbaatar showed 3\% MRSA in 207 Staphylococcus aureus strains investigated [40]. A later study reported that among 251 Staphylococcus aureus isolates, methicillin resistance was confirmed in $8.8 \%$ of isolates $(22 / 251)$ [41].

Interestingly, the consumption of beta-lactamase sensitive penicillins, including benzyl penicillin (J01CE01) has declined dramatically from $11.4 \mathrm{DDD} / 100$ bed days in 2013, consequently dropping to $0.2 \mathrm{DDD} /$ bed days in 2014 to no consumption in 2017. Hospital reports indicated that the resistance to these agents and ineffective treatment were the main reasons to stop procuring these antimicrobials. 
In addition, aggressive marketing of newer agents and a lack of comprehensive antibiotic-control programs might also have had an effect on consumption rates. Inappropriate use of antimicrobials and increasing number of resistant antimicrobial agents were found to be prevalent in Mongolia [42, 43].

4.1. Limitation. The reports from the Pharmacy Departments in two selected hospitals allowed for precise measurement of total amounts of drugs dispensed at the hospital, including judgement of the total dose, dosage, and volume of each individual prescription. However, due to the unavailability of data on antibiotics dispensed for outpatients which can be obtained with or without prescription from private pharmacies located within hospitals, the extent of antibiotic consumption can be systematically underestimated. The OTC sale of antibiotics has been prevalent in Mongolia and it has been addressed by the Government $[23,44,45]$.

\section{Conclusion}

The first hospital-based study of antibiotic consumption in Mongolia has demonstrated a measurably higher rate of antibiotic consumption in Mongolia than that in other countries. This is a critical first step in planning approaches to limit the emergence of antibiotic resistance through regular data gathering and analysis and the guidance of antibiotic prescribing.

\section{Abbreviations}

$\begin{array}{ll}\text { AMR: } & \text { Antimicrobial Resistance } \\ \text { ATC: } & \text { Anatomical Therapeutic Classification } \\ \text { DDD: } & \text { Defined Daily Dose } \\ \text { ESBL: } & \text { Extended Spectrum Beta Lactamase } \\ \text { OTC: } & \text { Over the Counter } \\ \text { UTI: } & \text { Urinary Tract Infection } \\ \text { STG: } & \text { Standard Therapeutic Guideline } \\ \text { WHO: } & \text { World Health Organization. }\end{array}$

\section{Data Availability}

The datasets used and analyzed during the current study are available from the corresponding author on reasonable request.

\section{Conflicts of Interest}

The authors declare that they have no conflicts of interest.

\section{Authors' Contributions}

GD, BS, HSB, TS, and MP carried out the study and drafted the manuscript. GS, OT, and BG participated in the design and revised the manuscript. GD performed the statistical analysis and revised the manuscript. BG conceived of the study, and participated in its design and coordination and revised the manuscript. All authors read and approved the final manuscript.

\section{Acknowledgments}

The authors would like to acknowledge all participating staff and directors of each hospital.

\section{References}

[1] Andersen, M., B. Wettermark et al., Drug Utilization Research: Methods and Applications, John Wiley \& Sons, 2016.

[2] F. Sjoqvist and D. Birkett, Drug Utilization J Introduction to Drug Utilization Research New York, WHO Office of Publications pp. 76-84, 2003.

[3] T. P. Van Boeckel, S. Gandra, A. Ashok et al., "Global antibiotic consumption 2000 to 2010: an analysis of national pharmaceutical sales data," The Lancet Infectious Diseases, vol. 14, no. 8, pp. 742-750, 2014.

[4] R. H. Vander Stichele, M. M. Elseviers, M. Ferech, S. Blot, and H. Goossens, "Group $†$ ESoACP. Hospital consumption of antibiotics in 15 European countries: results of the ESAC retrospective data collection (1997-2002)," Journal of Antimicrobial Chemotherapy, vol. 58, no. 1, pp. 159-167, 2006.

[5] S. Coenen, M. Ferech, F. M. Haaijer-Ruskamp et al., "European surveillance of antimicrobial consumption (ESAC): quality indicators for outpatient antibiotic use in europe," Quality and Safety in Health Care, vol. 16, no. 6, pp. 440-445, 2007.

[6] C. García-Rey, L. Aguilar, F. Baquero, J. Casal, and R. Dal-Ré, "Importance of local variations in antibiotic consumption and geographical differences of erythromycin and penicillin resistance in Streptococcus pneumoniae," Journal of clinical microbiology, vol. 40, no. 1, pp. 159-164, 2002.

[7] World Health Organization, "WHO report on surveillance of antibiotic consumption 2016-2018 early implementation," p. 127, 2018.

[8] Ministry of Health Mongolia, "Health development centre of mongolia. health indicators of mongolia," 2017.

[9] Ministry of Health Mongolia, "Health indicators of Mongolia-2016," 2016.

[10] Third State Hospital of Mongolia, "Annual statistics of the state third hospital of mongolia," 2013-2017.

[11] State Second Hospital of Mongolia, Annual statistics of the State Second Hospital of Mongolia, The State Second Hospital, Ulaanbaatar, MongoliaM. Shagdarsuren, Ed., 2013-2017.

[12] The Government of Mongolia, "Law of mongolia on procurement of goods, works and services with state and local funds," 2005.

[13] T. Tsilaajav, E. Ser-Od, B. Baasai, G. Byambaa, and O. Shagdarsuren, "Mongolia health system review," Health Systems in Transition, vol. 3, no. 2, 184 pages, 2016.

[14] World Health Organization, Anatomical Therapeutic Chemical (ATC) Classification System: Guidelines for ATC Classification and DDD Assignment, WHO Collaborating Centre for Drug Statisitcs Methodology, Oslo, 2013. 
[15] WHO Collaborating Centre for Drug Statistics Methodology, Guidelines for ATC classification and DDD assignment 2014, Oslo, Norway, 2013.

[16] R. Vander Stichele, M. M. Elseviers, M. Ferech, S. Blot, and H. Goossens, "European surveillance of antimicrobial consumption (ESAC): data collection performance and methodological approach," British Journal of Clinical Pharmacology, vol. 58, no. 4, pp. 419-428, 2004.

[17] D. Capellà, "Descriptive tools and analysis," WHO regional publications european series, vol. 45, pp. 55-78, 1993.

[18] World Health Organization, "WHO report on surveillance of antibiotic consumption: 2016-2018 early implementation," 2018. https://apps.who.int/iris/bitstream/handle/10665/27735 9/9789241514880-eng.pdf

[19] State Second General Hospital of Mongolia, "Antibiotic treatment guideline," 2014.

[20] State Third General Hospital of Mongolia, "Antibiotic treatment guideline," 2016.

[21] The Government of Mongolia, "The law on medicines and medical devices of mongolia," 1998.

[22] The Government of Mongolia, "The law on medicines and medical devices of mongolia (revised)," 2010.

[23] The Government of Mongolia, "National drug policy of mongolia," 2014.

[24] B.-E. Ider, A. Clements, J. Adams, M. Whitby, and T. Muugolog, "Prevalence of hospital-acquired infections and antibiotic use in two tertiary Mongolian hospitals," Journal of Hospital Infection, vol. 75, no. 3, pp. 214-219, 2010.

[25] V. Vlahovic-Palcevski, M. Morovic, and G. Palcevski, "Antibiotic utilization at the university hospital after introducing an antibiotic policy," European Journal of Clinical Pharmacology, vol. 56, no. 1, pp. 97-101, 2000.

[26] H. S. Blix and S. Hartug, "Hospital usage of antibacterial agents in relation to size and type of hospital and geographical situation," Pharmacoepidemiology and Drug Safety, vol. 14, no. 9, pp. 647-649, 2005.

[27] M. Čižman, "Nationwide hospital antibiotic consumption in slovenia," Journal of Antimicrobial Chemotherapy, vol. 66, no. 9, pp. 2189-2191, 2011.

[28] G. Dorj, D. Hendrie, R. W. Parsons, and B. Sunderland, "A questionnaire study of injections prescribed and dispensed for patients diagnosed with mild/moderate communityacquired pneumonia in Mongolia," PeerJournals, vol. 3, p. e1375, 2015.

[29] A. Versporten, G. Bolokhovets, L. Ghazaryan et al., "Antibiotic use in eastern europe: a cross-national database study in coordination with the WHO regional office for europe," The Lancet Infectious Diseases, vol. 14, no. 5, pp. 381-387, 2014.

[30] D.-S. Xie, L.-I. Xiang, R. Li, Q. Hu, Q.-Q. Luo, and W. Xiong, "A multicenter point-prevalence survey of antibiotic use in 13 chinese hospitals," Journal of Infection and Public Health, vol. 8, no. 1, pp. 55-61, 2015.

[31] K. G. Naber, H. Niggemann, G. Stein, and G. Stein, "Review of the literature and individual patients' data meta-analysis on efficacy and tolerance of nitroxoline in the treatment of uncomplicated urinary tract infections," BMC Infectious Diseases, vol. 14, no. 1, Article ID 628, 2014.

[32] R. Nakajima, T. Takano, V. Urnaa, N. Khaliun, and K. Nakamura, "Antimicrobial use in a country with insufficient enforcement of pharmaceutical regulations: a survey of consumption and retail sales in Ulaanbaatar, Mongolia," Journal Southern Med Review, vol. 3, no. 1, p. 19, 2010.

[33] G. Dorj, B. Sunderland, T. Sanjjav, G. Dorj, and B. Gendenragchaa, "Availability, affordability and costs of pediatric medicines in mongolia," BMC Pediatrics, vol. 18, no. 1, Article ID 149, 2018.

[34] World Health Organization, UNICEF, "Operational principles for good pharmaceutical procurement," 1999.

[35] S. Ghaffary, T. E. Maleki, J. Abdollahpor, and H. Hamishehkar, "Measurement and comparison of inpatient antibiotic use in five different hospitals in tabriz," Pharmaceutical Sciences, vol. 23, no. 1, pp. 37-41, 2017.

[36] I. Shalit, M. Low, E. Levy et al., "Antibiotic use in 26 departments of internal medicine in 6 general hospitals in Israel: variability and contributing factors," Journal of Antimicrobial Chemotherapy, vol. 62, no. 1, pp. 196-204, 2008.

[37] B. Baljin, G. Baldan, B. Chimeddorj et al., "Faecal carriage of gram-negative multidrug-resistant bacteria among patients hospitalized in two centres in ulaanbaatar, mongolia," PlOS ONE, vol. 11, no. 12, p. e0168146, 2016.

[38] Second State Hospital of Mongolia, "Annual report," 2018.

[39] Third State Hospital of Mongolia, "Annual report," 2018.

[40] D. Orth, K. Grif, L. Erdenechimeg et al., "Characterization of methicillin-resistant Staphylococcus aureus from ulaanbaatar, mongolia," European Journal of Clinical Microbiology and Infectious Diseases., vol. 25, no. 2, pp. 104-107, 2006.

[41] R. Nair, B. M. Hanson, K. Kondratowicz et al., "Antimicrobial resistance and molecular epidemiology of Staphylococcus aureus from ulaanbaatar mongolia," PeerJ, vol. 1, p. e176, 2013.

[42] G. Dorj, D. Hendrie, R. Parsons, and B. Sunderland, "An evaluation of prescribing practices for community-acquired pneumonia (CAP) in Mongolia," BMC Health Services Research, vol. 13, no. 1, Article ID 379, 2013.

[43] G. Togoobaatar, N. Ikeda, M. Ali et al., "Survey of non-prescribed use of antibiotics for children in an urban community in Mongolia," Bulletin of the World Health Organization, vol. 88, no. 12, pp. 930-936, 2010.

[44] Ministry of Health Mongolia, Strategy on Antimicrobial Resistance and Rational Use of Antibiotics, Ministry of Health, Ulaanbaatar, Mongolia, 2012.

[45] Ministry of Health of Mongolia, Ministry of Food and Light Industry of Mongolia. "Multi-sectoral National Action Plan on Antimicrobial Resistance (2017-2020),” Tech. Rep., 2017. 


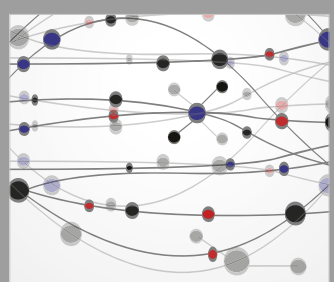

The Scientific World Journal
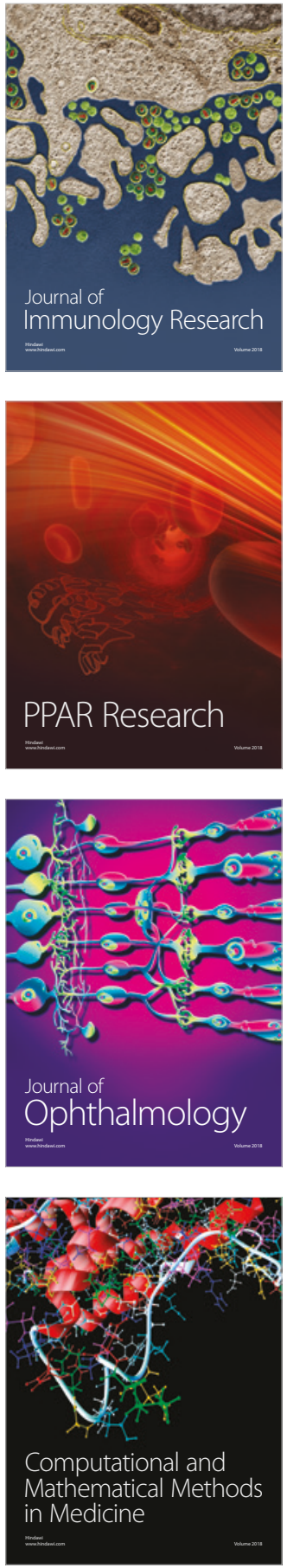

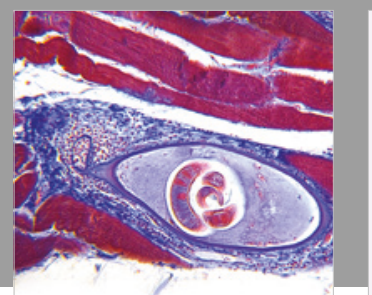

Gastroenterology Research and Practice



\section{Hindawi}

Submit your manuscripts at

www.hindawi.com
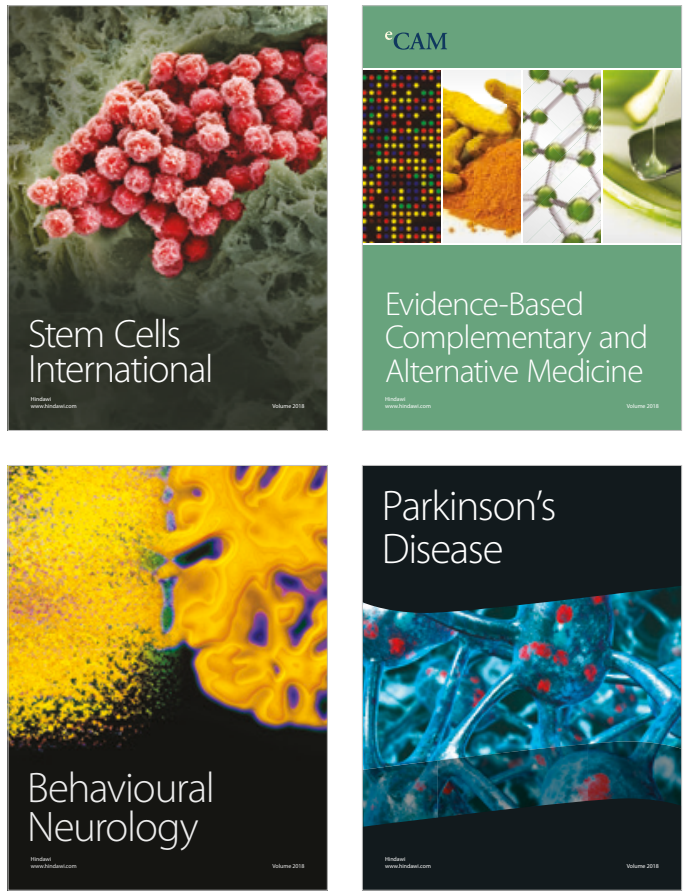

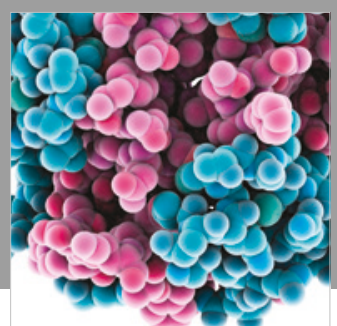

ournal of

Diabetes Research

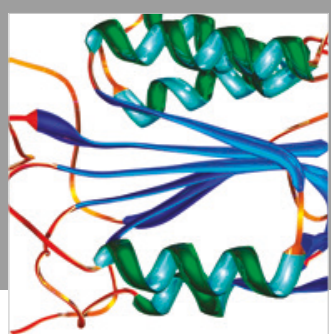

Disease Markers
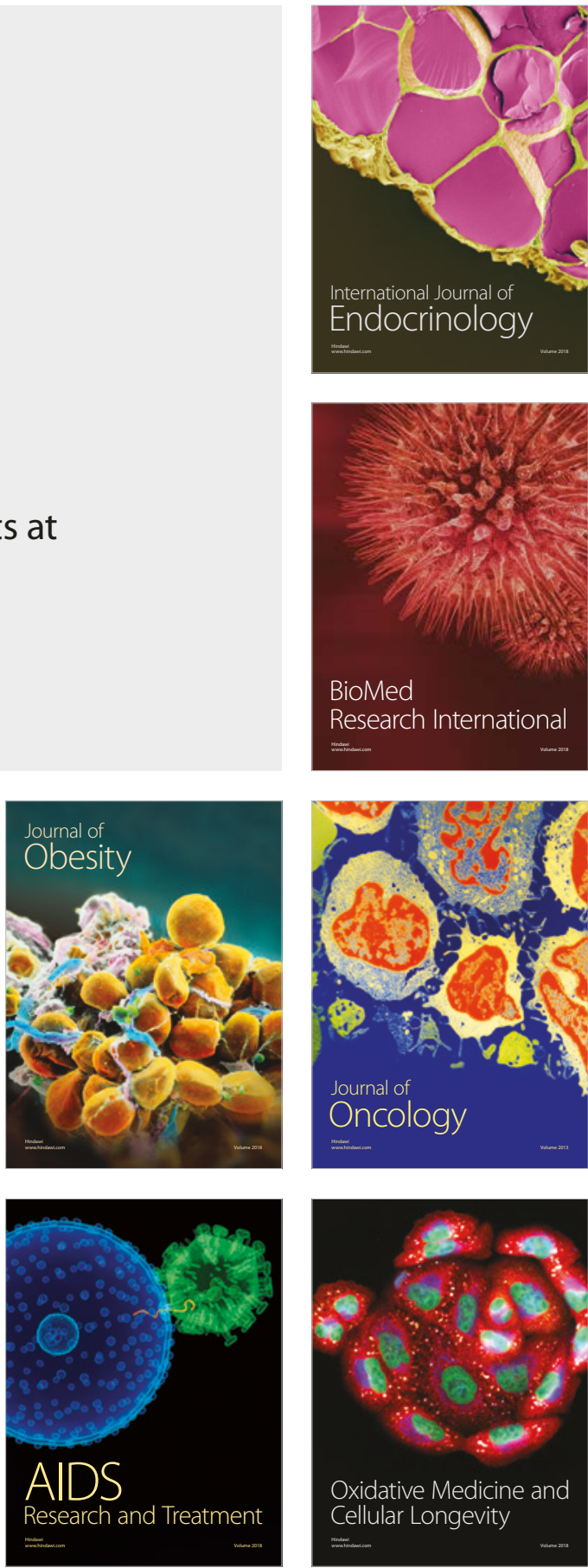